Article

\title{
Consumer Panel on the Readiness of Finns to Behave in a More Pro-Environmental Manner
}

\section{Noora Valkila * and Arto Saari}

Aalto University, School of Engineering, Department of Civil and Structural Engineering, P.O. Box 12100, FI-00076 Aalto, Finland; E-Mail: arto.saari@aalto.fi

* Author to whom correspondence should be addressed; E-Mail: noora.valkila@aalto.fi; Tel.: +358-500-405-446; Fax: +358-9-451-3758.

Received: 5 June 2012; in revised form: 29 June 2012 / Accepted: 29 June 2012 /

Published: 11 July 2012

\begin{abstract}
Due to climate change, there is an urgent need to take measures toward reducing greenhouse gases and energy consumption. It is therefore vital to examine peoples' attitudes and the potential for a more pro-environmental readiness. Consumer panels were used in the gathering of data, even with such small subsamples, statistical significance of difference cannot be assessed. The research subjects participating were randomly selected from two different residential areas and three different age groups. The consumer panels examined the environmental attitudes of the research subjects as well as their readiness to adopt a more pro-environmental lifestyle under four theme headings: Urban structure, household energy consumption, mobility and lifestyle. The results suggest that all the research subjects are very much ready to reduce their consumption, but not quite ready to invest in expensive, but environmentally-friendly equipment. Young and elderly research subjects seemed more prepared to make pro-environmental changes than middle-aged subjects. Place of residence also seemed to have an impact on the adoption threshold: Research subjects living in more densely populated suburbs seemed to be more willing to give up driving, whereas those living in sparsely populated areas seemed to be more willing to invest in expensive, but environmentally-friendly equipment and give up flying for vacations.
\end{abstract}

Keywords: consumer panel; environmental-friendliness; behavioral readiness; urban structure; sustainable consumption 


\section{Introduction}

Greenhouse gases (GHGs) emitted into the atmosphere cause global temperatures to rise, thus leading to a hazardous phenomenon known as climate change [1]. Now, there is an urgent need to take measures toward reducing greenhouse gases and adapting to the consequences of climate change (e.g., [2-4]). Human societies live in an environment whose care and management are everyone's shared social responsibility (e.g., [5,6]).

A study conducted by Heltberg et al. [3] examined crucial gaps occurring between people's current knowledge of climate and their actual behavior. Some of the existing literature on the subject does not take into consideration key impacts at the micro-level whatsoever. In other words, it overlooks important facts concerning how climate change threatens households in a variety of ways, such as jeopardizing people's finances, lifestyles and well-being. In many well-known studies, the focus is only on identifying climate change problems, imminent threats and direct impacts, while the indirect risks and impacts of climate change on people's lives is only given cursory attention.

Households comprise a crucial target group in increasing energy-efficiency [7-12]. Although precise figures are difficult to estimate, an approximately $10 \%$ reduction in emissions, at minimum, could be achieved by changing wasteful patterns in household energy consumption [13,14].

Climate change is a complex phenomenon, which is surrounded by a great deal of uncertainty $[15,16]$. Environmental considerations are today a ubiquitous part of all people's attitudes, as even ignorance regarding environmental issues is the expression of an attitude. Environmental attitudes (EA) are complex, individually personal experiences, which are, for the purposes of this study, only briefly defined in general terms below.

Environmental psychology experts, Kaiser et al. [17], discuss how a significant number of people's environmental attitudes are examined in their field: over half of the research conducted in environmental psychology involves environmental attitudes. Renowned environmental psychologist Milfont [18] concisely described the human expression of environmental attitudes as follows: "A psychological tendency that is expressed by evaluating perceptions of or beliefs regarding the natural environment, including factors affecting its quality, with some degree of favour or disfavour."

The attitude environment of households must be examined a bit more comprehensively. How can the environment be characterized? How well do people communicate their own attitudes and how many are prepared to change them?

Researchers have emphasized new types of research methods for collecting data directly from consumers on encountering climate change. Petersdorff et al. [19] stress the need for cross-disciplinary research. Heltberg et al. [3] state that data collection methods should combine longitudinal data collection and panel studies on households. Anable et al. [20] stress that people should be asked questions about climate change and their attitudes toward it. New methods should differ from conventional "top down" methods, such as interactive interviews, various types of conferences where the goal is not to achieve unanimity, but to address environmental issues from a variety of perspectives.

Consumer studies have long used various types of panels as a means for collecting data [21]. Panel studies are generally considered a solution that provides comprehensive and in-depth data on people's attitudes. As the authors of this study used the panel method in examining the attitudes and 
wishes of elderly people regarding services [22], they have recent experience in use of this method also in the implementation of elderly age group panels.

\section{Methods}

\subsection{Research Question and Themes Selected}

\subsubsection{Research Questions}

This study attempts to answer three research questions. The research questions are as follows:

1. What types of environmental attitudes do the research subjects have related to urban structure, household energy consumption, mobility and an environmentally-friendly lifestyle?

2. How does their readiness to make their behavior more pro-environmental seem?

3. Do their environmental attitudes and adoption threshold possibly differ from one another based on the place of residence and age of the research subjects?

\subsubsection{Themes Selected}

Four themes have been selected to illuminate the research questions. Selected themes are as examples of the actions how ordinary citizens can reduce energy consumption. All four themes were addressed in the same manner.

Theme I concerns with urban structure and enter into two different questions: (a) Place of residence and (b) infill development. Theme II concerns household energy consumption and enter into two questions: (a) compromising on living comfort and (b) investing in improving household energy-efficiency. Theme III concerns mobility and enter into two different questions: (a) daily mobility and (b) recreational mobility. Theme IV concerns with lifestyle and enter one question: (a) consumption.

Theme IV, lifestyle is not exactly in the same level than other themes but provides interesting information about consumption.

\subsection{Study Sites, Participant Selection and Eco-Panels}

\subsubsection{Study Sites}

The study was conducted in an identical manner in two different residential areas in Southern Finland, near the capital, Helsinki. The biggest differences between residential areas involved population density and access to public transportation. Southern Finland has numerous residential areas similar to those used in the study.

The first study site, Herttoniemi, is a model example of a typical, densely populated suburban district of Helsinki. It is located approximately 9 kilometers from the Helsinki city centre. The housing in Herttoniemi is very well established. Public transportation to Herttoniemi and within the area is good. The area has two metro stations and several local and long-distance bus stops. Services in the Herttoniemi area are comprehensive and diverse. Below are some numerical figures for Herttoniemi: Population: approx. 24,000, Area: approx. $6 \mathrm{~km}^{2}$ and Population density: approx. 3900 people $/ \mathrm{km}^{2}$ [23]. 
The other study site, Nurmijärvi, is a model example of a Finnish municipality with a significantly lower population density than Herttoniemi, a rural location and a large number of single-family homes. It is a well-known and popular growth community in the Greater Helsinki area. There is a large number of passenger cars in the area, with a high volume of single-driver commuter traffic. There is no rail traffic to the area and public bus service is quite limited. Below are some numerical figures for Nurmijärvi: Population: approx. 40,000, Area: approx. $370 \mathrm{~km}^{2}$ and Population density: approx. 110 people $/ \mathrm{km}^{2}$ [23].

The selection of study sites was also affected by the fact that the authors of this study had previously conducted, among other things, a study measuring the environmental attitudes and behavior of people in these areas (currently awaiting publication approval). The study in question found that there was a gap between the environmental attitudes and pro-environmental behavior of residents. The previous study in question provided the impetus for additional research, which is addressed in this study.

\subsubsection{Participant Selection}

The study sought to examine people falling into three different age groups. Age brackets were set based on the following principles:

The first group, Youth, comprised schoolchildren and students. In Finland, children begin school no earlier than 6 years of age. The group also included students, whose age bracket was expanded to cover 20 years, i.e., up to 26 years of age. The second group, Elderly, comprised elderly people. The official retirement age in Finland is 63 years. The group was expanded to cover 20 years, i.e., up to 83 years of age. The third group, Middle Age, comprised middle aged research subjects, possibly with families. Research subjects were therefore selected from the same age range (20 years) as the two groups above, but the age axis for this group fell roughly in the middle of the two other groups. Research subjects in the Middle Age group were between 34 and 54 years of age (Table 1).

Table 1. Age range in three selected research groups.

\begin{tabular}{lc}
\hline Group & Age (years) \\
\hline Youth & $6-26$ \\
Middle age & $34-54$ \\
Elderly & $63-83$ \\
\hline
\end{tabular}

It must be noted that only research subjects with families were selected for the Middle Age group based on the application location (day care center), which was indeed taken into consideration in forming the research plan. This emphasis on families was desirable because it could be reasonably surmised that the Youth and Elderly groups would have a large number of subjects living alone (students and the elderly). However, the Youth group would also comprehend schoolchildren still living at home, thus meaning that these subjects would also most likely have family.

Youth research subjects were sought from schools, day care centers and playgrounds, and elderly subjects from assisted living facilities or other gathering places. The researcher (the second author of this article) used public information to find Finnish-speaking schools, day care centers and playgrounds as well as assisted living facilities located within residential areas in the study site. Then he drew lots 
in each group for a primary consumer panel site as well as a second and third alternate site, in case no willing participants were found for the consumer panel at the primary site.

In the Herttoniemi area there were 6 possible alternatives for the Youth eco-panel, 7 for the Middle Age eco-panel and 4 for the Elderly eco-panel. In the Nurmijärvi area there were 22 possible alternatives for the Youth eco-panel, 21 for the Middle Age eco-panel and 9 for the Elderly eco-panel.

The researcher then contacted each site drawn in the lottery selection and asked permission to conduct a consumer panel on their premises. None of the second or third alternate sites were necessary, as every study site to which a request was submitted was keen to cooperate. The cooperation only required that the selected site would grant the researcher access to its premises, where he would convene a four-person panel from among the people patronizing/attending the facility and conduct the consumer panel at a prescribed time in a quiet conference room.

Table 2 lists the gender and age of persons participating in the consumer panels as background information as well as the code of their respective groups.

Table 2. Placement of research subjects (24) in six consumer panels as well as their gender and age as background data.

\begin{tabular}{lccccc}
\hline Area & Age group & Group & Person & Gender & Age \\
\hline Herttoniemi & Youth & $\mathrm{HY}$ & $\mathrm{HY}_{1}$ & Male & 17 \\
Herttoniemi & Youth & $\mathrm{HY}$ & $\mathrm{HY}_{2}$ & Male & 18 \\
Herttoniemi & Youth & $\mathrm{HY}$ & $\mathrm{HY}_{3}$ & Male & 18 \\
Herttoniemi & Youth & $\mathrm{HY}$ & $\mathrm{HY}_{4}$ & Female & 18 \\
\hline Herttoniemi & Middle age & $\mathrm{HM}$ & $\mathrm{HM}_{1}$ & Female & 35 \\
Herttoniemi & Middle age & $\mathrm{HM}$ & $\mathrm{HM}_{2}$ & Female & 36 \\
Herttoniemi & Middle age & $\mathrm{HM}$ & $\mathrm{HM}_{3}$ & Female & 44 \\
Herttoniemi & Middle age & $\mathrm{HM}$ & $\mathrm{HM}_{4}$ & Female & 50 \\
\hline Herttoniemi & Elderly & $\mathrm{HE}$ & $\mathrm{HE}_{1}$ & Female & 63 \\
Herttoniemi & Elderly & $\mathrm{HE}$ & $\mathrm{HE}_{2}$ & Female & 75 \\
Herttoniemi & Elderly & $\mathrm{HE}$ & $\mathrm{HE}_{3}$ & Male & 80 \\
Herttoniemi & Elderly & $\mathrm{HE}$ & $\mathrm{HE}_{4}$ & Female & 69 \\
\hline Nurmijärvi & Youth & $\mathrm{NY}$ & $\mathrm{NY}_{1}$ & Female & 22 \\
Nurmijärvi & Youth & $\mathrm{NY}$ & $\mathrm{NY}_{2}$ & Female & 23 \\
Nurmijärvi & Youth & $\mathrm{NY}$ & $\mathrm{NY}_{3}$ & Male & 24 \\
Nurmijärvi & Youth & $\mathrm{NY}$ & $\mathrm{NY}_{4}$ & Male & 21 \\
\hline Nurmijärvi & Middle age & $\mathrm{NM}$ & $\mathrm{NM}_{1}$ & Male & 40 \\
Nurmijärvi & Middle age & $\mathrm{NM}$ & $\mathrm{NM}_{2}$ & Female & 42 \\
Nurmijärvi & Middle age & $\mathrm{NM}$ & $\mathrm{NM}_{3}$ & Female & 45 \\
Nurmijärvi & Middle age & $\mathrm{NM}$ & $\mathrm{NM}_{4}$ & Female & 53 \\
\hline Nurmijärvi & Elderly & $\mathrm{NE}$ & $\mathrm{NE}_{1}$ & Male & 65 \\
Nurmijärvi & Elderly & $\mathrm{NE}$ & $\mathrm{NE}_{2}$ & Male & 72 \\
Nurmijärvi & Elderly & $\mathrm{NE}$ & $\mathrm{NE}_{3}$ & Female & 66 \\
Nurmijärvi & Elderly & $\mathrm{NE}$ & $\mathrm{NE}_{4}$ & Female & 81 \\
\hline & & & &
\end{tabular}




\subsubsection{Consumer Panels}

The study consumer panels lasted approximately 90 minutes and were conducted follows:

Once the panel was seated at a table, the researcher, who was the same for all groups (the first author of this study), explained that the study was being recorded. She then asked all the research subjects to place a piece of paper, on which their gender and age were written, on the table in front of them. This helped the researcher in making notes during discussions.

Prior to each theme being addressed (there were four themes), the researcher gave each research subject a piece of paper, on which there were a few facts about the theme being addressed and a question concerning their willingness to make changes. The research subjects were given time to peruse the paper, after which each panel member, in random order, explained their attitude toward the theme for approximately one minute. Within this one minute each panel member explained the issues which firstly come to their mind. A possible silence was also sort of explanation, it considered, but lack of knowledge cannot be an expression of an attitude.

Then, each panel member answered a question concerning their willingness to change on a scale of 1-4. After each panel member had presented their views, the theme was open for discussion for approximately 10 minutes.

The research subjects assessed their own willingness to change in theme questions being discussed, always using the following scale (Table 3):

Table 3. Scale by which research subjects assessed their own readiness to change with regard to the question asked.

\begin{tabular}{cc}
\hline Readiness value & Explanation \\
\hline 1 & Not at all ready \\
2 & Not very ready \\
3 & Quite ready \\
4 & Very ready \\
\hline
\end{tabular}

In other words, the higher the grade given, the more ready each subject felt they would be willing to become more pro-environmental in their behavior. If the research subject did not feel at all ready to change their behavior in a more pro-environmental direction, the grade given would be low.

All four themes were addressed in the same manner. The table below (Table 4) shows the themes and their question topics. Then, the theme-related questions are explained in greater detail in the same manner they were presented on cards handed out to the research subjects.

Table 4. Four themes addressed by consumer panels and the question topics related to them.

\begin{tabular}{clll}
\hline Theme & Explanation & \multicolumn{1}{c}{ Question A } & \multicolumn{1}{c}{ Question B } \\
\hline I & Urban structure & Place of residence & Infill development \\
II & Household energy & Compromising on living & Investing in improving \\
& consumption & comfort & household energy-efficiency \\
III & Mobility & Daily mobility & Recreational mobility \\
IV & Lifestyle & Consumption & - \\
\hline
\end{tabular}


Finally, the cards placed in front of each research subject at the beginning of a group theme discussion are presented. The cards helped the research subjects follow and comment on the discussion.

\subsubsection{Urban Structure}

\subsubsection{Place of Residence}

Energy consumption depends a great deal on the building stock and housing density (e.g., [24,25]) As single-family home areas are located far from city centers, residents must travel greater distances, thus resulting in a higher per-capita volume of traffic emissions. In cities, residents can choose to use, for example, public transportation or bicycling, thus reducing emissions.

Consumer panel discussion question: Would you be willing to live in an apartment building in the suburbs?

\subsubsection{Infill Development}

Increasing the density of Finland's urban structure would significantly reduce emissions, far more than dispersing it would [26]. Infill development would bring new housing and people (e.g., families with children) to existing residential areas. New residences are also better suited to housing the elderly than the area's existing residences. Likewise, the new residents use existing roads, streets and other infrastructure in the area. The growing population may also improve the area service offering.

Consumer panel discussion question: Would you be prepared to have a new house, approximately the same size as your house, built on the lot next to yours (provided that it would fit on the lot)?

\subsubsection{Household Energy Consumption}

\subsubsection{Compromising on Living Comfort}

Due to a colder than average climate, approximately $22 \%$ of Finland's primary energy goes to heating [27]. By reducing the indoor temperature one degree, heating energy consumption is reduced $5 \%$.

Consumer panel discussion question: Would you be prepared to drop your indoor temperature 2 degrees, thus reducing your heating energy consumption approximately 10\%?

\subsubsection{Investment in Improving Household Energy Efficiency}

Imagine that you are building a house. A new, electrically heated two-story house that meets existing building codes has an energy consumption of $152 \mathrm{kWh} /\left(\mathrm{m}^{2} \mathrm{a}\right)$. Energy consumption for a house with a ground source heat pump is almost half this - only $80 \mathrm{kWh} /\left(\mathrm{m}^{2} \mathrm{a}\right)$. The additional cost of installing a ground source heat pump is approximately $130 € / \mathrm{m}^{2}$. The return on investment at $3 \%$ real interest would be 18 years [28].

Consumer panel discussion question: Would you be prepared to make such an investment? 


\subsubsection{Mobility}

\subsubsection{Routine Mobility}

Private driving accounts for approximately $15 \%$ of a person's carbon footprint [29]. In Finland, there are over 2.5 million passenger cars, i.e., approximately one out of every two Finns owns a car. The number of cars has increased by approximately one-third since the beginning of the 1990s. The number of second cars has increased considerably: 32\% of Finns live in a household with at least two cars [30]. Using mass transit, the emissions produced are significantly lower than those produced by private driving. Walking and bicycling do not produce any emissions.

Consumer panel discussion question: Would you be prepared to give up your car right now, or hypothetically if you had a car?

\subsubsection{Recreational Mobility}

Air traffic warms the climate 2-5 times more than equivalent carbon dioxide emissions produced by traffic on the ground. In 2000, emissions produced by air traffic accounted for $4-9 \%$ of all anthropogenic climate warming [31,32]. Using the Flight Calculator, a single person's round-trip charter flight to Thailand produces over three tons of emissions. This quantity is equivalent to an estimated one-third of the greenhouse gases produced by an average Finn for one year [33]. Consumer panel discussion question: Would you be prepared to give up flying for vacations?

\subsubsection{Lifestyle}

Consumption

In Western culture, life meaning, satisfaction and approval are often sought through the consumption of goods and services. This activity, however, is one of the largest contributors to climate change. The state of the planet is unsustainable - the natural resources of 1.3 Earths would be needed in order to maintain the current wasteful level of consumption [34]. If everyone on the planet were to consume the same amount as Finns, 2.5 Earths would be needed to maintain the current way of life [35]. According to studies, a reduction in emissions of at least $10 \%$ could be achieved by simply changing the wasteful energy consumption patterns of households [11,14].

Consumer panel discussion question: Would you be prepared to cut your level of consumption?

\subsection{Methods used}

\section{Focus Group Discussion}

Focus group discussions were selected as the data collection method. The intention in focus group discussions is to set up a normal discussion with a relaxed atmosphere [36,37]. Through interaction between the members of the group in such a setting it is possible to obtain information that would otherwise not emerge [36-38], and, as Sim [39] points out, such group interaction can help individuals to study and clarify their own thoughts and ideas. The discussion participants can also offer support and encouragement to each other $[40,41]$. 


\subsection{Analysis}

The numerical values given by each member of the consumer panels for each theme were recorded and assigned codes later. These numerical readiness values were compiled in tables, which were used to compare different residential areas and age groups with one another.

With such small subsamples, statistical significance of difference cannot be assessed. The numerical values still give a hunch or idea, so they are presented in tables. Only the averages which are close to 1 or 4 are examined also verbally after the tables.

Group discussions recorded in consumer panels were transcribed word for word. These transcripts were analyzed in such a manner that any opinions repeated multiple times were highlighted. Conflicts occurring in the discussions were also highlighted. Unanimous group opinions for each question addressed in consumer panel discussions were highlighted in the analysis. An abridged version of these summations on each question reached in each consumer panel are presented at the end of the results section.

\section{Results}

The results of this study are presented in line with the implementation structure of the consumer panels, i.e., organized by theme as follows: First, the readiness of each research subject to change their behavior in a more pro-environmental direction as well as the calculated group-specific averages were presented. Then, research subjects' readiness to change their behavior in a more pro-environmental direction by area and then by age group was presented Finally, group-specific comments highlighted in consumer panels were presented.

\subsection{Readiness of Research Subjects to Change Their Behavior in a More Pro-Environmental Direction by Individual and by Group}

First, research subject readiness averages for different themes as well as by group and overall were presented (Table 5).

The research subjects would be very prepared to make cuts in their consumption levels.

As opposed to the other groups, both of the Elderly groups (Group HE and Group NE) were very prepared to give up driving and flying. Contrary, Middle Aged (HM and NM) were not willing to give up driving. Young Aged (HY and NY) were willing to allow infill development in their neighborhood, but Middle Aged (HM and NM) not.

Next, pro-environmental readiness averages for three different age groups by theme were presented (Table 6).

Based on the results of this survey, age seems to play a role in how ready people are to change their behavior in a more pro-environmental direction. In comparing the results of this study in each age group by theme, it would seem that age is a determining factor in the readiness to behave in a more pro-environmental manner, particularly where infill development and driving are concerned. 
Table 5. Research subject (24) readiness values by question, and consumer panel group averages and overall averages.

\begin{tabular}{|c|c|c|c|c|c|c|c|c|}
\hline \multirow[t]{2}{*}{ Person } & \multirow[t]{2}{*}{ Average } & \multicolumn{2}{|c|}{ Theme I Urban structure } & \multicolumn{2}{|c|}{ Theme II Household energy consumption } & \multicolumn{2}{|c|}{ Theme III Mobility } & \multirow{2}{*}{$\begin{array}{l}\text { Theme IV Lifestyle } \\
\text { (a) Consumption }\end{array}$} \\
\hline & & $\begin{array}{l}\text { (a) Place of } \\
\text { residence }\end{array}$ & $\begin{array}{c}\text { (b) Infill } \\
\text { development }\end{array}$ & $\begin{array}{l}\text { (a) Compromising } \\
\text { on living comfort }\end{array}$ & $\begin{array}{l}\text { (b) Investing in improving } \\
\text { household energy-efficiency }\end{array}$ & $\begin{array}{l}\text { (a) Daily } \\
\text { mobility }\end{array}$ & $\begin{array}{l}\text { (b) Recreational } \\
\text { mobility }\end{array}$ & \\
\hline $\mathrm{HY}_{1}$ & & 4 & 4 & 2 & 1 & 2 & 1 & 4 \\
\hline $\mathrm{HY}_{3}$ & & 4 & 4 & 3 & 1 & 1 & 1 & 4 \\
\hline $\mathrm{HY}_{4}$ & & 4 & 4 & 2 & 1 & 4 & 1 & 4 \\
\hline & Group HY & 4.0 & 4.0 & 2.5 & 1.3 & 2.0 & 1.3 & 4.0 \\
\hline $\mathrm{HM}_{3}$ & & 3 & 1 & 3 & 2 & 1 & 2 & 3 \\
\hline $\mathrm{HM}_{4}$ & & 4 & 1 & 4 & 1 & 1 & 1 & 4 \\
\hline & Group HM & 2.8 & 1.3 & 3.8 & 1.5 & 1.3 & 1.3 & 3.8 \\
\hline $\mathrm{HE}_{1}$ & & 4 & 4 & 2 & 1 & 4 & 4 & 3 \\
\hline $\mathrm{HE}_{2}$ & & 4 & 4 & 1 & 1 & 4 & 4 & 4 \\
\hline $\mathrm{HE}_{3}$ & & 4 & 3 & 2 & 2 & 4 & 4 & 4 \\
\hline $\mathrm{NY}_{3}$ & & 4 & 4 & 4 & 3 & 2 & 4 & 4 \\
\hline $\mathrm{NY}_{4}$ & & 4 & 4 & 4 & 4 & 3 & 3 & 4 \\
\hline & Group NY & 4.0 & 4.0 & 4.0 & 3.5 & 3.3 & 3.0 & 4.0 \\
\hline $\mathrm{NM}_{1}$ & & 1 & 1 & 2 & 4 & 1 & 1 & 2 \\
\hline $\mathrm{NM}_{2}$ & & 1 & 1 & 2 & 3 & 1 & 4 & 3 \\
\hline $\mathrm{NM}_{3}$ & & 1 & 1 & 3 & 4 & 1 & 1 & 2 \\
\hline $\mathrm{NM}_{4}$ & & 1 & 1 & 1 & 4 & 1 & 3 & 1 \\
\hline
\end{tabular}


Table 5. Cont.

\begin{tabular}{|c|c|c|c|c|c|c|c|c|}
\hline \multirow[t]{2}{*}{ Person } & \multirow[t]{2}{*}{ Average } & \multicolumn{2}{|c|}{ Theme I Urban structure } & \multicolumn{2}{|c|}{ Theme II Household energy consumption } & \multicolumn{2}{|c|}{ Theme III Mobility } & \multirow{2}{*}{$\begin{array}{l}\text { Theme IV Lifestyle } \\
\text { (a) Consumption }\end{array}$} \\
\hline & & $\begin{array}{l}\text { (a) Place of } \\
\text { residence }\end{array}$ & $\begin{array}{c}\text { (b) Infill } \\
\text { development }\end{array}$ & $\begin{array}{l}\text { (a) Compromising } \\
\text { on living comfort }\end{array}$ & $\begin{array}{l}\text { (b) Investing in improving } \\
\text { household energy-efficiency }\end{array}$ & $\begin{array}{l}\text { (a) Daily } \\
\text { mobility }\end{array}$ & $\begin{array}{l}\text { (b) Recreational } \\
\text { mobility }\end{array}$ & \\
\hline & Group NM & 1.0 & 1.0 & 2.0 & 3.8 & 1.0 & 2.3 & 2.0 \\
\hline $\mathrm{NE}_{2}$ & & 4 & 3 & 2 & 1 & 4 & 4 & 4 \\
\hline $\mathrm{NE}_{3}$ & & 3 & 2 & 1 & 2 & 4 & 4 & 4 \\
\hline $\mathrm{NE}_{4}$ & & 4 & 2 & 2 & 1 & 4 & 4 & 4 \\
\hline
\end{tabular}

Table 6. Readiness values of three different age groups to behave in a more pro-environmental manner by theme.

\begin{tabular}{|c|c|c|c|c|c|c|c|c|c|}
\hline \multirow{2}{*}{$\begin{array}{l}\text { Age } \\
\text { group }\end{array}$} & \multirow{2}{*}{$\mathrm{n}=$} & \multirow{2}{*}{ Figure } & \multicolumn{2}{|c|}{ Theme I Urban structure } & \multicolumn{2}{|c|}{$\begin{array}{c}\text { Theme II } \\
\text { Household environmental efficiency }\end{array}$} & \multicolumn{2}{|c|}{ Theme III Mobility } & \multirow{2}{*}{$\begin{array}{c}\text { Theme IV } \\
\text { Environmental } \\
\text { lifestyle }\end{array}$} \\
\hline & & & $\begin{array}{l}\text { (a) Place of } \\
\text { residence }\end{array}$ & $\begin{array}{l}\text { (b) Infill } \\
\text { development }\end{array}$ & $\begin{array}{l}\text { (a) Compromising on } \\
\text { living comfort }\end{array}$ & $\begin{array}{l}\text { (b) Investing in } \\
\text { improving household } \\
\text { energy-efficiency }\end{array}$ & $\begin{array}{l}\text { (a) Daily } \\
\text { mobility }\end{array}$ & $\begin{array}{c}\text { (b) } \\
\text { Recreational } \\
\text { mobility }\end{array}$ & \\
\hline Youth & 8 & Average & 4 & 4 & 3.3 & 2.4 & 2.6 & 2.8 & 4 \\
\hline $\begin{array}{l}\text { Middle } \\
\text { age }\end{array}$ & 8 & Average & 1.9 & 1.1 & 2.9 & 2.6 & 1.1 & 1.8 & 2.9 \\
\hline
\end{tabular}


All Youth research subjects participating in the consumer panels would allow a house roughly the same size as their own to be built on the adjacent lot, whereas Middle Age were not at all ready. The Elderly seemed to be very ready to give up driving, whereas Middle Age were not at all ready.

\subsection{Highlighted Research Subject Comments by Theme}

Next, research subject comments for and against moving in a more pro-environmental direction were presented. Comments were presented by theme, based on questions addressed in consumer panel discussions. Each panel presented one brief comment that best described the group regarding how they finally arrived at a unanimous opinion on the theme in question. The plus $(+)$ symbol preceding the comment indicated the group's generally positive attitude toward the question, while a minus $(-)$ symbol indicated a generally negative attitude.

Qualitative statements are only given as abridged version of these summations on each question reached in each consumer panel. Using some rigorous method such as thematic analysis would have been useful. Now the research subject comments by theme gives some idea of each consumer panel main points of each theme.

The comments are always presented in the same order: Herttoniemi Youth (HY), Herttoniemi Middle Age (HM), Herttoniemi Elderly (HE), Nurmijärvi Youth (NY), Nurmijärvi Middle Age (NM) and Nurmijärvi Elderly (NE).

\subsubsection{Living in an Apartment Building in the Suburbs}

+ Safe and convenient, assistance and friends always close at hand (HY).

- Every Finn's secret dream is to live in a single-family home, as there is plenty of land (HM).

+ Assistance from neighbors is always close at hand and the property management company takes care of the yard work. Loneliness is not a problem (HE).

+ Offers the most activities and services, easy choice, always something to do (NY).

- Suburban areas are dangerous, apartment buildings are inconvenient places to raise children. Exhaust fumes, noise, drunks, immigrants and others are nuisances (NM).

+ Convenient traffic connections, neighbors and services. Familiar stores and people (NE).

\subsubsection{Building a House on an Adjacent Lot}

+ It is good to place the houses right next to each other and then have large, public outdoor spaces (HY).

- Building density should not be increased, as this will compromise green zones and increase the level of noise and discord between neighbors (HM).

+ Nice to have more residents and social contacts, improved resident activity (HE).

$+\quad$ The more people, the better the activities and offering (NY).

- Peace and quiet in your own yard, do not want too much noise or troublemakers around (NM).

- Peace and quiet at home ruined by construction noise, can only see other buildings outside the window instead of nature, and unpleasant people might move into the building (NE). 


\subsubsection{Reducing the Indoor Temperature a Couple of Degrees}

- Even in the winter the house needs to be aired out, preferably keep common areas cooler (HY).

+ Can turn down the radiators instantly, usually a question of forgetfulness or laziness, more information should be provided on the subject and children should be raised to be accustomed to living at a cooler temperature (HM).

- It is possible to be more environmentally-friendly in many other matters, but one should not have to be cold at home (HE).

$+\quad$ This should be done by everyone, in public spaces, transportation and schools (NY).

- Will not achieve significant savings, one degree cooler is OK. Finland's cold climate requires that houses be kept warm (NM).

- One should be warm at home-make cuts somewhere else. Will not make much of a difference in global energy-efficiency (NE).

3.2.4. Investing in a Ground Source Heat Pump When Building a Single-Family House

- Unfair, builders have many other expensive investments to make (HY).

- Building a single-family home is already expensive, such a long-term investment is not very attractive (HM).

- Not an attractive investment, overall expensive and unreliable (HE).

+ If someone wants to build, environmental-friendliness costs money, sensible investment (NY).

+ There is a fairly quick return on the investment, single-family house builders should be more proactively provided with information on ground source heat pumps (NM).

- Difficult-sounding investment, high one-time cost and slow return on investment (NE).

\subsubsection{Giving Up Driving}

- Daily luxury, efficient vehicle, public transportation cannot compare (HY).

- Public transportation with children not an attractive option, the government should be better at drawing people away from private driving with incentives, such as discounted tickets for mass transit (HM).

+ Excellent public transportation, everyone should switch to using it - more demand will also increase the service offering (HE).

$+\quad$ It is a question of attitude. Taxis and even carpooling are great options, the trip is always more interesting than when sitting alone in a car (NY).

- Cars are a necessity, one could consider giving up their second or third car. Take the car's environmental-friendliness into consideration when buying (NM).

+ Car no longer necessary at an old age, enjoy a clear conscience by not polluting with it (NE). 


\subsubsection{Giving Up Flying on Vacation}

- Air travel is a problem, but the pleasure it brings outweighs considerations involving polluting the atmosphere (HY).

- Finns need to escape the long polar night to sunnier climates, flying offers a break from the workaday world, easier to make environmental choices in smaller matters (HM).

+ One's own country is the best place to vacation. Individual flying quotas, fines issued for flying too much (HE).

+ Vacationing at home will soon be a trend, celebrities and politicians should set the example (NY).

+/- With advances in technology comes natural degradation, but natural disasters harm the human race only over the long-term. Business air travel should be limited. Traveling by train and boat are good alternatives (NM).

+ People today do not know how to relax at home, so they fly abroad. Flying should be more expensive and flight taxes mandatory, so that unnecessary flying would be eliminated (NE).

\subsubsection{Cutting Down on Consumption}

+ There is no need to follow trends and constantly buy the latest technologies: Ready to use the library and borrow gear from friends (HY).

+ Especially ready to stop throwing away so much food and increase the recycling of clothes and toys (HM).

+ People should start paying attention to all the intangible things in life, like friends, nature and hobbies. Everyone already has enough things (HE).

+ Especially ready to buy gift cards and services for friends, not things. "Dumpster-diving" (recovering food that has been thrown away) is also an interesting option (NY).

- Not really ready to start cutting back, can do some fine tuning. Biggest splurge items is for the kids - real competitive gear. Consumerism is on the wane (NM).

$+\quad$ It is easy to give away unnecessary things and donating to charities feels good. Favoring locally produced food is a good thing $(\mathrm{NE})$.

\section{Discussion}

It is not possible to draw direct conclusions concerning the readiness of Finns to engage in more pro-environmental behavior based on the results of this study, but it does indicate that the degree of readiness can, indeed, vary widely in different areas and different age groups. Examining this readiness to adopt new behaviors also explains why there seems to be a gap between people's environmental attitudes and their actual behavior. If there is little willingness to make any changes, there is no reason to assume that a person will take any concrete action. The purpose of this study was not the generalizability of results directly for Finns, but more to provide an overview of a small group of research subjects and their readiness to adopt pro-environmental behaviors as well as to test the efficacy of a consumer panel in researching this subject matter. 
In examining the readiness averages of all research subjects in this study, it seems that the subjects are very ready to cut their level of consumption. Because it has been estimated that an approximately $10 \%$ reduction in emissions could be achieved simply by households making changes in wasteful energy consumption patterns $[13,14]$, it is good to know that people would be more willing to make cuts in their consumption levels (i.e., by minimizing purchases, recycling and making compromises in living comfort) than to make major environmental investments, such as a ground source heat pump, electric car or green electricity.

Based on the results of this study, it seems that residential area has an impact on what pro-environmental behaviors the research subjects would be willing to adopt. Residents of Nurmijärvi were more ready to make investments in ground source heat pumps and give up flying on vacation than residents in Herttoniemi. Herttoniemi residents are more ready to give up their cars than Nurmijärvi residents. Conversely, residents in both areas were almost equally ready to, for example, drop their indoor temperatures a few degrees.

In light of the results of this study, it seems that age is a defining factor in determining an individual's readiness to behave in a more pro-environmental manner. For example, Youth and Elderly research subjects would be very ready to live in an apartment building in the suburbs. Middle Age research subjects were also not as ready to accept infill development or give up driving their own car as the Youth and Elderly research subjects. This study still presents the quantitative findings from a very small group and it do not allow testing statistical significance. Qualitative statements give now some interesting findings, but they could be analyzed using some rigorous method such as thematic analysis for further research. The scope of further studies would be rather qualitative.

It is also difficult to compare the results of this survey with earlier, similar studies, as the structure of the study is new and the panel study approach, which is taken from marketing research, has not been applied in the study of people's environmental attitudes, behavior or readiness to adopt. These themes are usually approached using a survey form or individual interviews. In Finland, most empirical studies examining people's environmental attitudes and behaviors are conducted by means of survey forms mailed out to participants, whose rate of participation is also often quite low.

The reliability of consumer panels in this study is considered high, as the research subjects in all six consumer panels were selected randomly in the same manner. All the consumer panels followed the same prescribed discussion format and all discussions were led by the same researcher. The parsing and transcription of recorded group discussions and their analysis was always done in the same manner.

Still the panels were set up as 'eco panels', so then volunteer participants are maybe more likely to be environmentally friendly and cannot be taken to represent the population more generally. This must be noted as a limitation of generalization. Also the paper presents quantitative results from 24 participants, so the numbers are not compelling. The amount of participants is not massive but the idea was to provide an interesting point of view to the discussion of curbing climate change impacts through peoples' behavior, not to make statistical significance. As a result, this study offers excellent subject matter for further research and would be interesting to repeat in different residential areas, thus forming an even larger number of consumer panels in a wider variety of social groups, and their results could be compared with one another. It would also be interesting to form consumer panels in more precisely defined and widely varying groups. For example, young, high-income people with a 
high level of education that live in the Helsinki city center versus young, low-income people with a low level of education living far from the Helsinki city center in sparsely populated areas.

In general, the comments and their summaries collected from consumer panels were interesting and informative. It was nice to see that the research subjects were honest in their discussions, not trying to present themselves in the conventional image of a "better consumer", which can sometimes skew the results of this type of study. There is no justification to make any generalizations based on the comments, due to the small number of research subjects. The study results do, however, suggest that it is easy for people to explain both negative and positive behavioral readiness toward different themes, that they are interested in environmental matters, and dare to express even un-environmental opinions without causing any ill-will.

Within the framework of this study, consumer panels were found to be an enjoyable way to approach people's attitudes and their willingness to perhaps behave in a more pro-environmental manner. In the panels, group discussions were active, with participants further developing each other's ideas. No groups had any introverted research subjects, who did not dare to express their viewpoints. The risk in group discussions was, of course, that most group members ended up largely agreeing on the themes being addressed, even if they had started out with fairly divergent readiness values for the theme question.

\section{Conclusion and Recommendations}

The results of this study indicate that the research subjects are more ready to cut their level of consumption than to make major financial investments to enhance their environmental efficiency. Cutting consumption levels could be further encouraged by improving recycling possibilities. For example, glass jars and metal cans containing foodstuffs could be included in a deposit return scheme similar to the bottle return system used in Finland, which has been very successful. In addition to this, municipalities could organize monthly recycling events, in which people would bring unused things to a certain place, from which they could be taken by others needing them.

In order to get people to make financial investments in improving their environmental efficiency, more clearly presented information should be made available. Municipalities could also be responsible for this, organizing various theme weeks or providing information on an individual basis. Companies providing equipment and devices that enhance environmental efficiency should also focus on making the information they provide easy for everyone to understand as well as the equipment - and the estimated costs for it - easily available on the Internet.

It also seems that people are not willing to give up private driving unless the public transportation network is significantly more comprehensive. In this respect, Finnish transportation policy should tackle the challenge and invest even more in extending the public transportation network to also include remote areas. Furthermore, the frequency of public transportation service should be increased, schedules should be kept, and ticket prices should be decreased significantly to a level below that of private driving.

According to the results of this study, Youth and Middle Age research subjects are not very ready to give up flying on vacation. Air travel could, however, be replaced by domestic travel and going by ship and train, provided that these were made more attractive. Domestic travel service providers should 
also market the environmental aspect of domestic travel, getting people interested in various new alternatives for travelling in Finland.

It was very surprising to see how truly interested people were to participate in this study and spend their free time discussing environmental issues in a group, even though no financial incentive was offered. The research subjects often stayed on to continue discussing the themes addressed in the consumer panels even after the researcher had left. This would suggest to, for example, city councils and various committees, that people's activeness should be fully taken advantage of as well as that there may now be a need to coordinate a wide variety of volunteer work. It would be possible to organize multifaceted block activities and get citizens involved in practical actions.

\section{Conflict of Interest}

The authors declare no conflict of interest.

\section{References}

1. IPCC. Contribution of Working Group III to the Fourth Assessment Report; IPCC, New York, NY, USA, 2007; p. 776.

2. Giddens, A. The Politics of Climate Change; Mass Polity Press: Cambridge, USA and Malden, USA, 2008.

3. Heltberg, R.; Siegel, P.B.; Jorgensen, S.L. Addressing human vulnerability to climate change: Toward a 'no-regrets' approach. Glob. Environ. Change 2009, 19, 89-99.

4. Jorgensson, A.K.; Clark, B. Societies consuming nature: A panel study of the ecological footprints of nations, 1960-2003. Soc. Sci. Res. 2011, 40, 226-244.

5. Jorgenson, A.K. Consumption and environmental degradation: A cross-national analysis of the ecological footprint. Soc. Probl. 2003, 50, 374-394.

6. Downey, L. Environmental racial inequality in detroit. Soc. Forces 2006, 85, 771-796.

7. Bertoldi, P.; Ricci, A.; de Almeida, A. Energy Efficiency in Household Appliances and Lighting; Springer-Verlag: New York, NY, USA and Berlin, Germany, 2000.

8. Herring, H. Energy efficiency-A critical view. Energy 2006, 31, 10-20.

9. Stern, N. The Economics of Climate Change: The Stern Review; Cambridge University Press: Cambridge, USA, 2007.

10. Yamaguchi, Y.; Shimoda, Y.; Mizuno, M. Transition to sustainable urban energy system from a long-term perspective: Case study in a Japanese business district. Energy Build. 2007, 39, 1-12.

11. Abrahamse, W.; Steg, L. How do socio-demographic and psychological factors relate to households' direct and indirect energy use and savings? J. Econ. Psychol. 2009, 30, 711-720.

12. Andreassi, L.; Ciminelli, M.V.; Feola, M.; Ubertini, S. Innovative method for energy management: Modelling and optimal operation of energy system. Energy Build. 2009, 41, 436-444.

13. Abrahamse, W.; Steg, L.; Vlek, C.; Rothengatter, J.A. A review of intervention studies aimed at household energy conservation. J. Environ. Psychol. 2005, 25, 273-291.

14. Darby, S. The Effectiveness of Feedback on Energy Consumption: A Review for DEFRA of the Literature on Metering; The Environmental Change Institute, University of Oxford: Oxford, UK, 2006. 
15. Bord, R.J.; Fisher, A.; O'Connor, R.E. Public perceptions of global warming: United States and international perspectives. Clim. Res. 1998, 11, 75-84.

16. Lorenzoni, I.; Langford, I.H. Climate Change Now and in the Future: A Mixed Methodological Study of Public Perceptions in Norwich (UK); CSERGE Working Paper ECM 01-05; CSERGE: Norwich, UK, 2001.

17. Kaiser, F.G.; Wölfing, S.; Fuhrer, U. Environmental attitude and ecological behavior. J. Environ. Psychol. 1999, 19, 1-19.

18. Milfont, T.L. Psychology of Environmental Attitudes: A Cross-cultural Study of Their Content and Structure. Ph.D. Dissertation, University of Auckland, Auckland, New Zealand, Unpublished work, 2007.

19. Petersdorff, C.; Boermans, T.; Harnish, J. Migitation of $\mathrm{CO}_{2}$ emissions from the EU-15 building stock. Environ. Sci. Pollut. Res. 2006, 13, 350-358.

20. Anable, J.; Lane, B.; Kelay, T. An Evidence Base Review of Public Attitudes to Climate Change and Transport Behavior; Final Report; UK Department for Transport, London, UK, 2006.

21. Sudman, S.; Ferber, R. Consumer Panels; Marketing Classics Press: Decatur, GA, USA, 1979.

22. Valkila, N.; Saari, A. Consumer panel study on elderly people's wishes concerning services. Arch. Gerontol. Geriatr. 2010, 51, e66-e71.

23. Statistic Finland. Finland by Numbers 2011; Statistics: Helsinki, Finland, 2011.

24. Dodman, D. Blaming cities for climate change? An analysis of urban greenhouse gas emissions inventories. Environ. Urban. 2009, 21, 185-201.

25. Norman, J.; MacLean, H.L.; Kennedy, C.A. Comparing high and low residential density: Life-cycle analysis of energy use and greenhouse gas emissions. J. Urban Plan. Dev. 2006, $132,10-21$.

26. Lahti, P.; Moilanen, P. Urban Community Structure and Greenhouse Gas Emissions. From Base 2005 to 2050; Finnish Environment 12; Ministry of the Environment: Helsinki, Finland, 2010.

27. Statistics Finland. Energy Statistics Yearbook 2010; Statistics: Helsinki, Finland, 2010.

28. Saari, A.; Kalamees, T.; Jokisalo, J.; Michelsson, R.; Alanne, K.; Kurnitski, J. Financial viability of energy-efficiency measures in a new detached house design in Finland. Appl. Energy 2011, 92, 76-83.

29. Seppälä, J.; Mäenpää, I.; Koskela, S.; Mattila, T.; Nissinen, A.; Katajajuuri, J.-M.; Härmä, T.; Korhonen, M.-R.; Saarinen, M.; Virtanen, Y. Finland's National Economy of Material Environmental Impact Assessment by ENVIMA Model, Finnish Environment 20; Ministry of the Environment: Helsinki, Finland, 2009.

30. TraFi Roadtravel. Vehicles on the Road in Finland 2010, 2010. Available online: http://www.trafi.fi/ (accessed on 11 July 2012).

31. Climate Action Network Europe. Clearing the Air. The Myth and Reality of Aviation and Climate Change. Federation for Transport and Environment, A T\&E, CAN-Europe: Brussels, Belgium, 2006.

32. European Environment Agency. Annual European Community Greenhouse Gas Inventory 1990-2005 and Inventory Report 2007; EEA Technical Report No 7; European Environment Agency: Copenhagen, Denmark, 2007.

33. Flight calculator. 2011. Available online: http://www.lentolaskuri.fi (accessed on 11 July 2012). 
34. Worldwatch Intstitute, 2010. The State of the World 2010. Available online: http://www.worldwatch.org/ (accessed on 11 July 2012).

35. WWF. Living Planet Report, 2008. Available online: http://wwf.panda.org/about_our_earth/ all_publications/living_planet_report/(accessed on 11 July 2012).

36. Krueger, R. Focus Groups. A Practical Guide for Applied Research, 2nd ed.; Sage: Thousand Oaks, CA, USA, 1994.

37. Kitzinger, J. Qualitative research. Introducing focus groups. Br. Med. J. 1995, 311, 299-302.

38. Morgan, D. Focus Groups as Qualitative Research; Sage: Thousand Oaks, CA, USA, 1988.

39. Sim, J. Collecting and analysing qualitative data: Issues raised by the focus group. J. Adv. Nursing 1998, 28, 345-352.

40. Cedergren, L.; Bylund, E.; Hollo, A. Dialogues with Patients. Handbook on Collecting and Making Use of Information on Patients' Experiences; Spri: Realtryck, Stockholm, 1995.

41. Eskola, J.; Suoranta, J. Introduction to Qualitative Research; University of Lapland: Rovaniemi, Finland, 1996.

(C) 2012 by the authors; licensee MDPI, Basel, Switzerland. This article is an open access article distributed under the terms and conditions of the Creative Commons Attribution license (http://creativecommons.org/licenses/by/3.0/). 